\title{
DE CURAÇAOSCHE BEGROOTING VOOR 1920
} DOOR

\author{
MR. B. DE GAAY FORTMAN.
}

In een onzer leidende politieke organen werd onlangs in een overzicht der rijksmiddelen de opmerking gemaakt, dat aan de departementen de gewoonte bestaat de middelen wat krap en de uitgaven wat ruim te rekenen, om zich zooveel mogelijk te verzekeren van de kans, dat de eindafrekening meevalt. Dit moge in het algemeen zoo zijn, het departement van koloniën volgt voor de Curaçaosche begrooting een ander systeem, dat bijna even zeker steeds tegenvalt bij het vaststellen van het slot der rekening van uitgaven en ontvangsten. Wanneer in de Memorie van toelichting bij de ontwerp-begrooting voor 1920 de volgende vergelijking tusschen de eindcijfers van dit ontwerp met die der begrooting voor 1920 wordt gemaakt:

uitgaven . . . . . . $f$ 1.905.344.$f$ 2.028.80\% - inkomsten . . . . - 1.070.574.- 989.884 - -

nadeelig verschil . . $f$ 834.770.dan verheugt zich met een doode musch, wie hierin meent te lezen eene verlichting van de lasten van het moederland of - wil men - eene verbetering van den geldelijken toestand der kolonie. Immers twee ongelijksoortige grootheden worden hier naast elkaar gezet en met elkaar vergeleken. De cijfers over 1919 zijn niet die der toenmalige ontwerp-begrooting maar de vermoedelijke eindcijfers tot op het oogenblik der dagteekening van bovengenoemde M. v. t. ${ }^{1}$ ) met inbegrip dus van een of meer wet-

\footnotetext{
1) Alstoen was ook nog aanhangig een ontwerp van wet tot verhooging der uitgaven over 1919 met niet minder dan $f$ 103.060.-
} 
ten tot wijziging en verhooging dier begrooting. Het oorspronkelijk geraamde cijfer der uitgaven voor 1919 was $f$ 1.887.736.- - dus een $f$ 20.000.- minder dan dat voor 1920. En al komen ditmaal op de begrooting geen memorieposten voor, de verwachting is blijkens de M. v. t. niet ongegrond, dat er in den loop van 1920 aanleiding en behoefte genoeg zal zijn, om het ramingscijfer der uitgaven belangrijk te verhoogen. Immers in dit stuk wordt gezegd: „Echter moet voor 1920 nog rekening gehouden worden met eenige vrij aanzienlijke uitgaven, welke in de onderhavige begrooting niet zijn opgenomen, omdat ten aanzien van enkele daarvan nog overleg met den Gouverneur gaande is, terwijl voor andere op de totstandkoming van wettelijke regelingen, waarop de betrokken voorzieningen zullen berusten; moet worden gewacht".

Het ligt trouwens in de historische lijn, dat de bijdragen van het moederland aan de kolonie jaarlijks - met enkele uitzonderingen - belangrijk toenemen. Van $f$ 168.181. - in 1901 was het jaarlijksch tekort in 1910 geklommen tot $f 350.848$.- , dus verdubbeld, en daarna waren de cijfers:

$$
\begin{array}{ll}
1911 f 354.843 .29 & 1913 \cdot f 401.669 .02 \frac{1}{2} \\
1912-424.912 .18 & 1914-522.822 .47
\end{array}
$$

De cijfers der latere jaren, die nog niet vastgesteld zijn, zullen geen andere uitkomst opleveren, naar te verwachten is, als men bedenkt, dat toen niet alleen de inkomsten gedrukt werden door de gevolgen van den oorlog, maar ook de dure havenverbetering werd voortgezet, en de nieuwe gezondheidsdienst - om ons hiertoe te bepalen niet geringe geldelijke eischen is gaan stellen.

Ook buiten den oorlog heeft de toename van de middelen, zonder de bijdragen van het moederland, geen gelijken tred gehouden met de stijging der uitgaven, gelijk uit onderstaande cijfers blijkt:

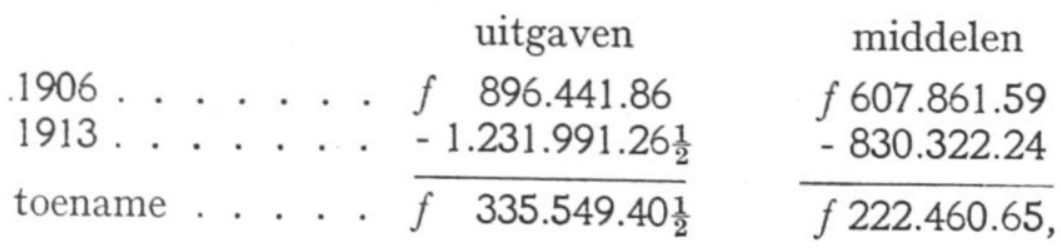


terwijl na 1913 tot de raming der loopende begrooting de uitgaven gestegen zijn met niet minder dan $f$ 673.353.en de ontvangsten met slechts $f$ 240.252.-

Deze inleidende beschouwing plaatsen wij naast hetgeen wij verleden jaar ${ }^{1}$ ) opmerkten over den strijd tusschen den Kolonialen Raad eenerzijds en Bestuur en Regeering anderzijds in verband met het "steeds meer bezwaren" der begrooting en over de splitsing in ,gewone" en ,buitengewone" uitgaven of, zooals men de laatste thans noemt, ,uitgaven die door leening kunnen worden gedekt"' 2 ).

De inrichting der begrooting, zooals zij ditmaal bij de Tweede Kamer is ingediend, is er voor de belangstellenden niet beter op geworden. De uitgewerkte en toelichtende staten der uitgaven en inkomsten, waaronder de Memorie van toelichting van den Gouverneur aan den Raad, zijn vervallen ${ }^{3}$ ). Wij hadden gaarne gezien, dat de tot dusver gebruikelijke stukken juist waren uitgebreid, en aangevuld met alle in de kolonie over de begrooting gewisselde stukken en de notulen van den Raad. Wel heeft de Regeering zich voorgesteld in het bijzonder verschillen tusschen de ingediende ontwerpen en de in de kolonie voorloopig vastgestelde begrootingen meer uitvoerig toe te lichten, maar o. i. zijn deze verschillen al in de onderhavige begrooting niet voldoende tot hun recht gekomen. Met name, gelijk wij zullen zien, laat de M. v. t. niet overal voldoende recht wedervaren aan het gevoelen van den Kolonialen Raad, waar dit afwijkt van dat van het Bestuur.

Uit de ter zake der Surinaamsche begrooting gewisselde stukken, waaraan het bovenstaande over de inrichting der begrootingsstukken is ontleend, zij ook deze opmer-

1) Zie aflevering no. 3 Juli 1919 van dit tijdschrift, bladz. 186-190.

$\left.{ }^{2}\right)$ De Koloniale Raad voelde weinig voor die euphemistische onderscheiding, en ook wij hebben verklaard daaraan weinig waarde te hechten, daarom volsta hier de mededeeling, dat de begrooting 1920 onder de uitgaven, die door leening kunnen worden gedekt, wil brengen een bedrag van $f$ 120.000.- voor verdere verbetering van de haven van Curaçao en voor kosten van onderzoek naar de mogelijkheid om Willemstad van eene drinkwaterleiding te voorzien.

$\left.{ }^{3}\right)$ Voor de kamerleden zijn deze stukken ter inzage gelegd. 
king overgenomen, dat Minister De Graaff evenmin als zijne ambtsvoorgangers zijne medewerking wenscht te verleenen tot eenen zoogenaamden verkoop van onze West-Indische koloniën. Bemoedigend voor Curaçao is daarbij des Ministers opmerking, dat de moeilijkheden tot bevordering der welvaart in deze kolonie minder groot zullen zijn dan die om Suriname tot bloei te brengen. In dit verband vinde eene plaats de voorzichtige waarschuwing van den Heer Kraus in de Eerste Kamer, die ook in de kolonie ongetwijfeld weerklank vinden zal: „Ik heb de geringe beteekenis van de kolonie Curaçao in het algemeen expres naar voren gebracht, om bij voorbaat te waarschuwen tegen alle maatregelen, deze kolonie betreffende, waaraan geldelijke offers van veel beteekenis zouden zijn verbonden. Ik denk bijv. aan grootsche havenplannen, die in de lucht mochten zitten, niet alleen voor Curaçao, maar ook voor de andere eilanden, zooals St. Martin, waar men een omvangrijke havenstudie op touw heeft gezet en waarop in 's Ministers Memorie van Antwoord aan de Tweede Kamer wordt gedoeld. Ik wil de Regeering dus allerminst drijven tot uitgaven, die buiten verhouding zouden staan tot de beteekenis van de streken, waar het hier om gaat, buiten verhouding tot de belangen, die er door zouden worden gediend".

In Curaçao besteedt de Raad gewoonlijk één avond aan de mondelinge behandeling der begrooting. Dit heeft er toe geleid, dat deze vergadering al meer op het nippertje gehouden wordt. Bijna had dit dezen keer den heeren parten gespeeld. Tot laat in den avond is geboomd over de motie-Winkel, die, door bijna alle leden onderteekend, met algemeene stemmen op twee na aangenomen werd, en toen was 't haast-je rep-je om nog net Zaterdagnacht of misschien reeds Zondagochtend gereed te komen. De besprekingen dier motie, hoewel formeel behoorende tot het begrootingsdebat, kunnen wij goeddeels buiten beschouwing laten, omdat zij in hoofdzaak liepen over de benoeming van den heer Mr. De la Try Ellis tot lid van den Raad buiten de aanbeveling om. Slechts volledigheidshalve zij opgemerkt, dat in het V.V. der Eerste Ka- 
mer is uitgesproken, dat men ,de houding van den Minister in deze volkomen gerechtvaardigd (achtte) en er zich in (verheugde), dat door bedoelde benoeming een ietwat billijker samenstelling van den Raad in verband met de verschillende bevolkingsgroepen is verkregen", hetgeen de heer Van Kol bij de mondelinge behandeling in die Kamer nader bepleitte. Volgens het stelsel der evenredige vertegenwoordiging, merkte deze afgevaardigde op, hebben de Roomsch-Katholieken niet meer dan $\frac{1}{6}$ van de hun toekomende zetels. Afgezien van de vraag, of dit stelsel voor de koloniale „vertegenwoordiging” wenschelijk zou zijn, dient opgemerkt, dat niet 2 maar 3 Roomsch-Katholieken in den Raad zitten, zoodat zij althans $\frac{1}{4}$ van het hun ,toekomende" zouden bezetten.

De motie-Winkel hield echter meer in. Afkeuring wordt erover uitgesproken, dat de Regeering in het Moederland ,,in den laatsten tijd herhaaldelijk . . . . afwijkt van de beslissingen van den Raad", waardoor het aanzien van dit college ernstig zou worden geschaad en in breede kringen ernstig ontstemming veroorzaakt zou worden tegen het Nederlandsch bestuur in het algemeen, wat noch in het belang van het Moederland noch in dat der kolonie werd geacht. Dit onderwerp leent zich ongetwijfeld tot begrootingsdiscussies, in zooverre het de verhouding tusschen Regeering en Raad raakt, en de wijze, waarop het „vertegenwoordigend" college in de kolonie meent, hare taak te moeten opvatten en vervullen. Onzerzijds is voor het oogenblik niets toe te voegen aan hetgeen wij verleden jaar hebben opgemerkt hieromtrent, te minder nu deze zaak, helaas, geen onderwerp van diepgaande gedachtenwisseling uitmaakte tusschen Regeering en Staten-Generaal ${ }^{\mathbf{1}}$ ). In den Raad zelf heeft de heer Maduro dit punt het meest zakelijk behandeld. Door hem werd erop gewezen, dat tal van uitgaven, die ook hij noodig en nut tig achten zou, zijne instemming niet hebben, nu de kolonie zelfs voor hare hoog noodige uitgaven op den steun van het moederland aangewezen is. In deze omstandig-

$\left.{ }^{1}\right)$ Verleden jaar konden wij reeds vermelden wat de heer van Kol hiervan toen in de Eerste Kamer gezegd heeft. 
heden, meende de spreker, dat de Raad uiterst voorzichtig moest zijn ,,in het voteeren van uitgaven van welke niet van meet af vaststaat, dat zij binnen afzienbaren tijd tot den vooruitgang der kolonie in ruime mate zullen medewerken". Onder deze uitgaven bracht de heer Maduro niet die voor handel en scheepvaart, de ,slagaders der kolonie", en dankbaar aanvaardde hij den steun van het moederland, om de kolonie zoodanig uitterusten, dat zij, als de tijden weer eenigszins normaal zouden zijn, gereed zou mogen zijn om op te eischen haar rechtmatig deel in de ontwikkeling van deze elementen der volkswelvaart. Ook eene waarschuwing, om de belastingschroef niet al te zeer aan te draaien, meende de heer Maduro niet achterwege te mogen laten ${ }^{1}$ ).

Evenals alle jaren werd het onderwijs besproken. Ook over het openbaar onderwijs kunnen Raad en Bestuur maar niet tot overeenstemming komen. Zelfs niet over de vraag, of het zoo slecht is als gezegd wordt, en nu al jaren lang, dan wel aan de betere hand is. Intusschen maakt de verdediging van den gemachtigde van het Bestuur meer den indruk van eene verklaring van den minder gunstigen toestand dan van eene bestrijding van den in zijn oordeel niet malschen maar ongetwijfeld zakelijken aanvaller. Niet vergeten mag echter worden, dat het hierbij in hoofdzaak gaat om het onderwijs aan de Hendrikschool te Willemstad op Curaçao, een wel zeer belangrijk onderdeel van het geheele onderwijs maar daarom nog niet maszgebend voor de geheele kolonie.

In de Eerste Kamer is de kwestie van de „,voertaal” van het onderwijs ter sprake gekomen. Eene verordening is ingediend, die op de benedenwindsche eilanden het Nederlandsch voertaal maken wil, en op de bovenwindsche eilanden aan het Engelsch de plaats laten, die het

1) Sedert is door den Gouverneur eene commissie benoemd, om hem te dienen van advies met het oog op de noodzakelijkheid om naar middelen uit te zien, die de koloniale kas stijven en de financieele lasten van het moederland ten opzichte der kolonie eenigszins verlichten.' In de Eerste Kamer heeft de Minister meegedeeld, dat deze commissie ook onder de oogen zal zien de vraag, of algeheele herziening van het belastingstelsel gewenscht is. 
als omgangstaal van de jeugd toekomt. Dit laatste had de instemming van den heer Kraus. In verband met de emigratie naar Cuba enz. hebben de maatregelen van het bestuur betreffende het vervoer van personen van Curaçao naar het buitenland de instemming van den Raad verkregen, die ook op zoodanige maatregelen voor de andere eilanden aandrong. Het onderhoud der achtergelaten gezinnen is een moeilijk vraagstuk, waarvoor de bestuursgemachtigde ook weinig raad wist. Tot oplossing is het nog niet gebracht. Het Koloniaal Verslag 1919 doet hierover intusschen eenige niet ongunstige mededeelingen. Teekenend is, dat van deze emigratie zelf de M. v. a. aan de Eerste Kamer ook geen latere cijfers dan die voor 1918 wist te geven nl. 1381 emigranten van de drie benedenwindsche eilanden, hetgeen ,niet zeer onrustbarend” werd genoemd. De Heer Van Kol dacht daarover anders, en ook heeft de Amigoe di Curaçao voor Februari-half Juni 1919 alleen voor het hoofdeiland al 1300 emigranten opgegeven, en erop gewezen, dat het totaalcijfer voor Curaçao reeds $10 \%$ der bevolking, voor Aruba nog hooger was.

Bevredigende toezeggingen kreeg de heer Statius Muller op zijne klachten over de huisvesting van gevaarlijke patiënten in het krankzinnigengesticht. En de heer Van der Veen Zeppenfeldt bereed zijn jaarlijksch stokpaardje, waaraan de Paardenbaai van Aruba zijn naam ontleent.

In het V. V. van den Kolonialen Raad was gevraagd, of het aan het Bestuur bekend was, dat er werkgevers op Curaçao waren, die aan hun werkvolk boeten oplegden, en men wenschte eene bepaling om de werklieden tegen willekeur te beschermen. Het Bestuur vond hierin aanleiding mee te deelen, dat met den Minister van Koloniën in het algemeen van gedachten gewisseld werd over de wenschelijkheid van invoeging der „sociale wetten" van het moederland in de Curaçaosche wetgeving, maar blijkens de M. v. a. aan de Eerste Kamer schijnt de sedert opgetreden minister daarvoor niet veel te voelen.

Overgaande tot de hoofdpunten van hetgeen de behandeling der artikelen bracht, vermelden wij als een ver- 
blijdende nieuwe post, die, hoewel niet gering, geen tegenkanting ontmoet heeft, een bedrag van $f$ 10.000.uitgetrokken voor eene openbare boekerij en leeszaal.

Vooral bij twee onderwerpen moeten wij stilstaan. Bij nota van wijzigingen is eene uitgave van $f 6.500$. - aan den Raad gevraagd voor verzorging en opvoeding van verwaarloosde jongens en meisjes. f 5.500.- hiervan zouden aan het Apostolisch Vicariaat worden gegeven als subsidie voor de oprichting en instandhouding van een gesticht voor verwaarloosde jongens, dat op Scherpenheuvel zou geopend worden. De raming was zuinig: 4 fraters als leerkrachten à $f 700$. - en voeding, kleeding enz. van 15 jongens à $f 180$.- - Tegen het bedrag op zichzelf zal de Raad wel geen bezwaar hebben gehad, maar het ging hierbij om de oude principieele kwestie. „Vadertje Staat" moest het doen, en de zuinige Raad scheen voor een oogenblik te vergeten, dat dit heel wat meer kosten zou. Men kwam kortweg met een amendement, om het bedrag onveranderd te laten en de omschrijving van de post te laten luiden: „kosten van een Gouvernementsinrichting ten behoeve van verwaarloosde kinderen". Dat kan toch moeilijk ernstig werk genoemd worden. Wat het Vicariaat, de beschikking hebbende over de plantage Scherpenheuvel en over de liefde en toewijding van het verplegend personeel, kan doen met eene subsidie van $f$ 6500.-, kan het Gouvernement niet doen met hetzelfde bedrag, als het alles, ook de oprichting, daarvan moet betalen. En wat is er tegen, wanneer alleen Roomsche kinderen worden opgenomen, gelijk het bestuur in uitzicht heeft gesteld? Wij zijn het er volkomen mee eens, dat Protestantsche en Israëlietische kinderen in dit gesticht niet thuis behooren; vreest men eene eenigszins belangrijke toename der criminaliteit onder de jeudige leden van andere kerken, dan ligt niet aanstonds de conclusie voor de hand, dat het Gouvernement hier maar zorgen moet op zoo veelzijdige wijze, dat allen bevredigd worden, doch wel deze, dat dan ook andere kerken of vereenigingen deze zaak dienen ter hand te nemen. De godsdienst, wie zal het ontkennen, is een machtige factor in de opvoeding, 
vooral van de verwaarloosde en misdadige jeugd. Het Gouvernement zou voor een onoplosbaar raadsel komen te staan, als het, nog wel voor $f$ 6.500.--, eene inrichting in het leven moest roepen, waarin de kinderen van iedere godsdienstige richting eene opvoeding krijgen zouden overeenkomstig hun geloof. Desalniettemin de Raad heeft met 9 tegen 4 stemmen het bovengenoemde amendement aangenomen. De Regeering heeft echter de oude post hersteld, en - gelijk te verwachten was - is zij daarbij niet op tegenstand gestuit. De Eerste Kamer sprak in haar V. V. uitdrukkelijk uit, dat zij zich met die post geheel vereenigen kon, ,,al waren eenige leden van meening, dat deze taak meer tot die van den Staat behoort".

Heel wat sterker indruk maakt de bestrijding in den Raad van de uitgaven op landbouwgebied. Jarenlang heeft de Koloniale Raad zich verzet tegen eene vaste aanstelling van den landbouwkundige, steeds de nutteloosheid betoogende van tal van uitgaven voor proefnemingen enz., op dit gebied gedaan. Niet alleen heeft dit weinig gebaat, maar nu komt de Gouverneur zelfs met een voorstel, om een hulp-landbouwkundige aan te stellen voor de bovenwindsche eilanden, als hoedanig ,een geschikt jongmensch" aan den Minister gevraagd was. De oplossing, die de Raad aan de hand deed, lag van zijn standpunt voor de hand: is er op St. Martin c. a. een landbouwkundige noodig, stuurt dan den man, dien wij hier beneden de wind over hebben naar boven, en - Gij, Bestuur, en wij, Raad, zijn beiden tevreden. En toen het Bestuur dit niet wilde, deed de Raad het zelf, hij zou het althans gedaan hebben, als hij hierin iets te doen had gehad, want de Minister herstelde de door den Raad verworpen posten voor den hulp-landbouwkundige, en de Kamers - de Eerste zelfs met eenig enthousiasme gingen mee. En toch waren de argumenten van den Raad niet zwak, ofschoon misschien wat overdreven geformuleerd. In de M. v. t. geeft de Minister deze argumenten aldus weer: op landbouwgebied zou men sinds de aanstelling van den landbouwkundige geen stap zijn vooruitge- 
gaan; geen enkele proef zou resultaat gehad hebben; de landbouwondernemingen zouden thans bovendien het bezwaar ondervinden, dat de arbeidsloonen zeer gestegen zijn, en vele arbeiders naar den vreemde trekken. Het lijkt meer dan het is, als daartegenover gewezen wordt op de invoering van nieuwe soorten van graan- en voedergewassen, het telen van uitgezochte zaaizaden, de verbetering van de groententeelt, de demonstratieproeven voor grondbewerking en de invoering van doelmatige landbouwwerktugien. Zou het aan de aandacht van den $\mathrm{Mi}$ nister ontgaan zijn, wat de Gouverneur in zijne M. v. a. geschreven heeft over ,de hoofdredenen waarom op Curaçao geen meerder gebruik is gemaakt van de motorploeg"?

Tot zoover in hoofdzaak de behandeling der begrooting in de kolonie. In Nederland was weder de behandeling in de Eerste Kamer heel wat belangrijker dan die aan de overzijde van het Binnenhof. Teleurstellend in hooge mate was de geheele onbekendheid van den nieuwen Minister met de kolonie en de eischen harer belangen; zelfs deed het eenigszins vreemd aan, dat de Minister zich zoo voortdurend op die onwetendheid beriep. Trouwens in de Tweede en in de Eerste Kamer zijn ook door de leden opmerkingen gemaakt, die niet altijd blijk gaven van een goed op de hoogte zijn van de toestanden en regelingen in de kolonie.

In de Tweede Kamer is weinig gezegd, dat niet beter in de Eerste gezegd is door de heeren Kraus en Van Kol, die beiden de kolonie uit eigen aanschouwing kennen. De heer Van Vuuren in de Tweede heeft nog eens over de gelijkstelling van bijzonder en openbaar onderwijs gesproken, een onderwerp, waarover waarschijnlijk binnen niet al te langen tijd het laatste woord zal kunnen gesproken worden, als de maatregelen, die uitvloeisel zijn van de thans juist aangenomen wijziging van het Regeeringsreglement, aan de orde zijn. Ook over de samenstelling van den Kolonialen Raad, door de heeren Van Vuuren en Van Kol besproken, is weinig nieuws gezegd, en wij hebben niet den indruk, dat de Minister bij 
al zijne toezeggingen van „overwegingen” enz. spoedig dit inderdaad niet gemakkelijke vraagstuk zal oplossen.

Wel treffend was, dat èn in de Tweede èn in de Eerste Kamer zooveel aandacht gewijd werd aan de toestanden op de Bovenwindsche eilanden. De daar verleden jaar gaande gemaakte beweging voor ,,bestuurlijke scheiding” schijnt door het bezoek van den Gouverneur reeds weer bezworen, al blijft het natuurlijk gewenscht, dat de daar ongetwijfeld noodige verbeteringen aangebracht worden. Ook heeft de Minister meegedeeld, dat de bovengenoemde afscheiding in hoofdzaak om geldelijke redenen niet uitvoerbaar is. En wij hebben vernomen, dat de uitzending van den nieuwen gezaghebber voor de drie eilanden bedoelde ,om .... de verheffing van den economischen toestand van de bevolking te bevorderen". Vergissen wij ons niet, dan is dit het eerste licht, dat over dezen maatregel opgaat. Juist lijkt intusschen het betoog van den heer Kraus, dat het althans weinig zin schijnt te hebben, om de belangen der eilanden in handen te leggen van den Kolonialen Raad, die ter plaatse niet bekend is, en de plaatselijke behoeften en omstandigheden niet voldoende kan beoordeelen. Het is daarom goed, dat dezelfde afgevaardigde, daarin gesteund door den Heer Van Kol, op enkele dier belangen heeft gewezen, als o.a. op dat van de zoutindustrie op St. Martin.

Ter sprake is nog gekomen de onvastheid in de regeling der bezoldigingen, waarover buiten de begrooting om ook de Koloniale Raad met algemeene stemmen een afkeurend oordeel heeft uitgesproken, De Minister heeft het stelsel van persoonlijke toelagen verdedigd als geschikt „om aan de kolonie de beschikking te verzekeren over tijdelijk uit te zenden personeel" ; op deze wijze zouden dan ook èn de directeur van openbare werken èn zijn collega van den openbaren gezondheidsdienst voor de kolonie behouden zijn gebleven. Dat laatste is eene blijde tijding, maar neemt niet weg, dat het systeem, dat bovendien wel eens den indruk maakt van een systeemloos loven en bieden, tegenover tal van ambtenaren, en wel de oudere maar daarom nog niet minder goede, wijl zij min- 
der veeleischend waren, onbillijk werkt. Er zal ook nog wel een tusschenweg zijn tusschen het thans gevolgde stelsel en het denkbeeld, , dat de bezoldigingen zich moeten richten naar de behoeften van voor de onderscheidene betrekkingen in de kolonie beschikbare krachten".

Evenals verleden jaar heeft de heer Bulten in de Tweede Kamer de aandacht van den Minister gevestigd op de struisvogelteelt, waarop, naar hij zeide, ook de Gouverneur de aandacht gevestigd had. De heer Van Kol deelde in de Eerste Kamer ook een en ander mee over deze industrie, maar geheel nieuw was het antwoord van den Minister, dat het advies van den Gouverneur hierover „,allerminst onverdeeld gunstig is".

Belangrijke verhoogingen, in het begin zeiden wij het reeds, zijn in den loop van het jaar nog te wachten ten opzichte van deze begrooting. De M. v. t. stelt in uitzicht duurtebijslagen of verhooging der bezoldigingen of beiden, inrichting van eenen mijnbouwkundigen dienst, watervoorziening, toelagen van voor den dienst in de kolonie uittezenden personeel boven de wettelijke bezoldigingen, verruiming der landsbijdragen voor het bijzonder onderwijs, oprichting van een West-Indisch pensioenfonds, verhooging van pensioenen, voorziening in het verkeer en vervoer tusschen de verschillende eilanden der kolonie, waarvoor allemaal uitgaven zullen noodig zijn, die niet gering zullen zijn.

Over eenige van bovenstaande onderwerpen heeft de Koloniale Raad zich reeds uitgesproken. De gelden voor de inrichting van eenen mijnbouwkundigen dienst zijn gevoteerd; die voor de toelagen boven de wettelijke bezoldigingen zijn, gelijk wij reeds opmerkten, verworpen. Of dit laatste iets geven zal? Het is niet waarschijnlijk, wanneer het juist is, dat hiermee niet anders bedoeld wordt dan sanctionneering van eene reeds eenige jaren gevolgde praktijk. Ook de andere onderwerpen zullen allicht aan het oordeel van den Raad onderworpen worden, afgezien hiervan, dat voor eenige eerst wettelijke voorzieningen noodig zijn. Reeds in het afgeloopen jaar heeft de Gou- 
DE CURAÇAOSCHE BEGROOTING VOOR 1920.

verneur, nadat de begrooting definitief in het moederland was vastgesteld, in eene zoogenaamde wenschelijkheidsverordening de Koloniale Raad zijn gevoelen laten uiten over wijziging dier begrooting, een staatsrechtelijk novum, althans in de Curaçaosche staatkundige geschiedenis, waarvan, als wij het wel hebben, aan den nieuwen Gouverneur de eer der vinding toekomt.

De Raad heeft in de motie-Winkel ten slotte het vertrouwen uitgesproken, dat de Regeering ,,in den vervolge meer dan tot dusverre rekening zal willen houden met het oordeel van den Kolonialen Raad". Zou dit vertrouwen na de behandeling dezer begrooting versterkt zijn? Misschien hooren wij dit over een paar maanden als de nieuwe begrooting aan de orde komt.

Zooals gezegd, de Minister heeft het niet onder stoelen en banken gestoken, dat hij van de West-Indische koloniën niet zooveel afwist. Waarschijnlijk ook daarom is in alle toonaarden voorgedragen het overwegen, aandacht schenken, met belangstelling nagaan enz., van tal van kwesties, ook van zulke, die rijp zijn voor oplossing door menschen, die er reeds langer over hebben gedacht. Het had o. i. dan ook in de lijn van den Minister gelegen, en gaarne hadden wij gezien, dat eenige toezegging in die richting was gedaan, als eene welwillende houding aangenomen was tegenover het denkbeeld van den heer Van Kol, bij de Surinaamsche begrooting geopperd, nl. om eene commissie van deskundigen tot des Ministers voorlichting in het leven te roepen, een „Koloniale Raad in Nederland” van personen, ,die op de hoogte zijn van de algemeene politieke toestanden in Suriname en Curaçao, die trouw de pers volgen, die de vroegere literatuur kennen en die een uitvoerige studie van die koloniën hebben gemaakt". De zaak zij nòg aan den Minister ter ernstige overweging aanbevolen.

Dordrecht 19 Maart/April 1920. 